\title{
EFFECTIVENESS OF LOW-COST CUSTOMIZED SADDLE PILLOW ON PAIN IN POST-EPISIOTOMY PATIENTS
}

\author{
NAIR SHALINI KRISHNAN, ANBUPRIYA M*, SIVAKUMAR VPR
}

Department of Physiotherapy, SRM University, Kattankulathur, Kancheepuram - 603 203, Tamil Nadu, India. Email: shaliniphysio11@gmail.com

Received: 24 June 2017, Revised and Accepted: 31 August 2017

ABSTRACT

Objective: To examine the effectiveness of customized saddle pillow for pain in post-episiotomy patients and also to analyze the duration of sitting for breastfeeding and other functional activities following episiotomy.

Methods: A total of 28 postnatal mothers who have undergone episiotomy were included in the study based on the inclusion criteria and were divided conveniently into an experimental group $(n=16)$ and control group $(n=12)$. Both the groups received the conventional physiotherapy protocol, but experimental group patients, in addition, were provided with customized saddle pillow. Customized saddle pillow was used by the patients from postnatal day (PND) 0 to PND 2. Pre- and post-test values for pain were assessed through the numerical pain rating scale (NPRS). In addition, data such as duration of sitting for breastfeeding and other functional activities were collected through sitting tracker.

Results: The study manifested the effectiveness of low-cost customized saddle pillow in reducing perineal pain ( $\mathrm{p}=0.01$ ) and increase in sitting duration ( $\mathrm{p}=0.01$ ) in post-episiotomy patients compared to the control group.

Conclusion: Among the postnatal mothers selected for the study the mothers who used customized saddle pillow experienced a reduction in pain as well as the better sitting duration for breastfeeding. The research recommends mothers who underwent episiotomy to use the low-cost saddle pillows for healthier breastfeeding and pain-free life.

Keywords: Postnatal mothers, Episiotomy, Saddle pillow, Pain and breastfeeding.

(C) 2017 The Authors. Published by Innovare Academic Sciences Pvt Ltd. This is an open access article under the CC BY license (http://creativecommons. org/licenses/by/4. 0/) DOI: http://dx.doi.org/10.22159/ajpcr.2017.v10i12.20932

\section{INTRODUCTION}

Episiotomy refers to incision of the perineum during the second stage of delivery to spread the pelvic outlet and to prevent delay in fetal head delivery [1]. This is done during the second stage of the labor to expand the opening of the vagina to prevent tearing of the perineum during the delivery of the baby. This is one of the most common procedures in the maternal-child care. Episiotomy is thought to minimize the risk of laceration and over stretching of the perineal tissue. This procedure is usually done when the vaginal opening does not stretch enough to allow the baby to get delivered without tearing the surrounding tissue.

There are four main types of episiotomy: medio-lateral, median, lateral, and J-shaped. According to a study conducted in 18 tertiary care hospital in India among 120,243 vaginal deliveries, episiotomy has been performed in $63.4 \%(n=76,305)$ cases [2]. Most physicians believe that an episiotomy shortens the pushing phase and that reduces the chance of the baby suffering from oxygen deprivation and thus protecting the fetal skull. Episiotomy is performed in various cases like fetal shoulder dystocia where the shoulder of the baby gets lodged under the mother's symphysis during birth, vaginal breech birth, forceps or vacuum extraction-assisted births, an obvious risk for serious tears of the soft tissues of the perineum region. Episiotomy has some complications, including perineal pain and discomfort, bleeding, infection, damage to anal sphincter and mucosa, wound opening, difficulty in sitting and holding one's infant, disruption of maternal-infantile relationships, and reduction of sexual desire. Therefore, wound healing is of particular importance [3-5].

Perineal pain due to episiotomy can restrict sitting position which is one of the important functional positions for a postnatal mother because one of the best and recommended positions for breastfeeding is sitting. Most of the functional activities are compromised in sitting because of the episiotomy induced perineal pain. There are various treatment methods available in the field of physiotherapy to reduce this perineal pain, namely, cryotherapy, ultrasound, scar mobilization, and sitz bath $[6,7]$. Many studies are conducted using these treatment methods to reduce the pain. Almost all the treatment methods have proved positive in reducing the episiotomy pain. Except for sitz bath, every treatment was given in lying or side lying position, but no studies have documented the relevant improvement in their sitting tolerance. Hence, there is a need in obstetric physiotherapy to provide a comfortable sitting position for postnatal mothers to enhance breastfeeding.

Along with the modalities, donut pillow is also used for episiotomy pain. Although donut pillows are usually prescribed for coccydynia, they are also used for episiotomy patients. However, donut pillows can place pressure on the coccyx by isolating the coccyx and ischial tuberosities and are more useful for treating rectal pain [8]. Hence, there is a need to concentrate more on relieving the perineal pain as well as pressure in sitting position; this gave rise to the idea of making a customized saddle pillow. This customized saddle pillow is $16 \times 18$ inches in size. It has three parts - anterior pubic part, middle perineal part, and posterior coccyx part. It is made up of soft foam throughout, but in the anterior aspect near the symphysis pubis region, the foam is hard to prevent the adduction of lower extremities. This pillow has a hollow space $(18 \times 6 \times 13)$ in the center to accommodate the perineal region so that the pressure over that region is released and the patient feels more comfortable while sitting.

\section{METHODS}

The study was conducted in the inpatient Department of Obstetrics and Gynaecology, SRM Medical College Hospital and Research Centre.

Inclusion and exclusion criteria

The patients who underwent episiotomy, age group ranging from 21 to 33 years, primi and multigravida patients. Perineal tear patients were excluded from the study. 


\section{Experimental design}

Based on the inclusion criteria, 28 postnatal mothers who have undergone episiotomy were selected for the study. After taking a formal consent letter, the subjects were divided conveniently into experimental group $(n=16)$ and control group $(\mathrm{n}=12)$. Both the study groups received the conventional physiotherapy protocol, but experimental group patients, in addition, were provided with the customized saddle pillow. Customized saddle pillow was used by the patients from postnatal day (PND) 0 to PND 2. This pillow was given to patients after they were shifted to the labor ward approximately $6 \mathrm{hrs}$ after the procedure. Pre- and post-test values for pain were assessed through the numerical pain rating scale (NPRS). Pre-test was taken on PND 0 and post-test was taken on both PND 1 and PND 2.

Furthermore, additional data such as duration and frequency of sitting for breastfeeding, duration, and frequency of sitting for other functional activities were collected through "sitting tracker." Sitting tracker consisted of demographic data (name, age, and PND) with 2 columns, one in which time was mentioned as $1 \mathrm{hr}$ slots representing $24 \mathrm{hrs}$ and in another column, patients were asked to tick and mention the duration when they sat for either breastfeeding or other functional activities. All the data were collected and documented immediately with one copy sent to the principal investigator.

\section{Statistical analysis}

All the data collected were analyzed using t-test to determine the effectiveness between the experimental group and the control group to find out the significant difference through NPRS. All the statistical analyses were performed using SPSS 16.0 statistical software, $p=0.05$ $95 \%$ significant levels were considered significant throughout the study.

\section{RESULTS}

Among the 28 postnatal mother selected for the study based on inclusion criteria, 4 patients from the experimental group, and 2 patients from the control group withdrew the study as they were posted for puerperal sterilization and hence the follow-up of these patients was not available.

Hence, the study was conducted with the other 22 subjects (Table 1), the $(p<0.05)$, there is a significant difference within the experimental group regarding the pain (using NPRS) and duration of sitting using the customized saddle pillow intervention.

According to Table 2, the $\mathrm{p}<0.05$, hence, there is a significant difference within the control group regarding the pain (using NPRS) and duration of sitting.

According to Table 3 , the $p<0.05$, the experimental group is effective when compared to the control group in reducing pain among episiotomy patients.

According to Table 4 , the $\mathrm{p}<0.05$, hence the experimental group is effective when compared to the control group in increasing the duration of sitting among episiotomy patients.

\section{DISCUSSION}

Perineal pain is the most common complaint among women after delivery causing anxiety and stress. Moreover, perineal pain after delivery also has negative impacts on women's performance in taking care of their infants and family members [3-5]. Subsequently, the present study aimed to compare the two groups with respect to pain intensity as well as sitting duration. The results of this study showed a significant difference between the experimental and control groups in terms of pain with the usage of customized saddle pillow and also sitting duration while breastfeeding.

There are many studies conducted to reduce the episiotomy pain such as a study conducted by Belezaa et al. stated that after 2 minutes of application, cryotherapy was effective in women in the immediate postpartum period after vaginal birth with episiotomy [6]. Likewise, another study conducted in the year 2016 as proved that there was no significant difference between the groups regarding perineal healing after low-level laser therapy [7]. All these studies concentrated primarily on pain but did not provide information about their sitting tolerance. A study conducted by Reading et al. stated all women reported some degree of discomfort after the episiotomy, with many declaring the pain to be severe [9]. This pain arising due to episiotomy can lead to postpartum depression. Postpartum depression could lead to a drastic reduction in mother's breast milk production and her willingness to breastfeeding [10].

In this study, more attention was given to sitting position to enhance breastfeeding. According to the results emphasized in this study (Table 4), it is very much clear that using customized saddle pillow improved the sitting duration of postnatal mothers who have undergone episiotomy thereby proving the efficacy of the customized saddle pillow.

The physiology behind increased sitting tolerance can be attributed to the construction of saddle pillow. Since it helps in relieving the pressure in episiotomy region and thereby increases the blood flow in the perineal region, the pain was reduced, and the patient could sit for a longer duration. Moreover, the wedge in the anterior aspect of the pillow prevented the adduction of leg in long sitting position, thus providing a comfortable position for breastfeeding in their immediate postnatal period. Furthermore, the pillow is cost effective and easy to carry so it can be made available in the postnatal ward and used for the betterment of new mothers.

Initially, patients had difficulty to accommodate in sitting position above the pillow due to lack of familiarity but later on the comfort level of pillow made it user-friendly for the mothers. Clinically, we could observe that mothers who were using the customized saddle pillow become more confident and were able to lead an independent life in the ward. Usage of customized saddle pillow has made the patients accomplish their personal needs earlier than the other group. Thus, this customized saddle pillow has its own advantage as it concentrates on the healing of perineal pain, improves sitting

Table 1: Within experimental group (A) for comparing pain and sitting duration

\begin{tabular}{|c|c|c|c|c|c|}
\hline \multirow[t]{3}{*}{ Study groups } & \multicolumn{4}{|l|}{ Paired differences } & \multirow[t]{3}{*}{ Significant (two-tailed) } \\
\hline & \multirow[t]{2}{*}{ Mean \pm standard deviation } & \multirow[t]{2}{*}{ Standard error mean } & \multicolumn{2}{|c|}{$\begin{array}{l}95 \% \text { confidence } \\
\text { interval of the } \\
\text { difference }\end{array}$} & \\
\hline & & & Lower & Upper & \\
\hline \multicolumn{6}{|l|}{ Pair 1} \\
\hline A pre NPRS - A post-NPRS 1 & $2.500 \pm 0.674$ & 0.195 & 2.072 & 2.928 & $0.001^{*}$ \\
\hline \multicolumn{6}{|l|}{ Pair 2} \\
\hline A post-NPRS 1 - A post-NPRS 2 & $3.583 \pm 0.793$ & 0.229 & 3.080 & 4.087 & $0.001^{*}$ \\
\hline \multicolumn{6}{|l|}{ Pair 3} \\
\hline A PND 0-1 hrs - A PND 1-2 hrs & $-1.1250 \pm 0.6784$ & 0.1958 & -1.5560 & -0.6940 & $0.001^{*}$ \\
\hline
\end{tabular}

*Significance at $95 \%$ confidence interval. Since the $\mathrm{p}$ value is less than 0.05 , there is a significant difference within the experimental group regarding the pain (using NPRS) and duration of sitting using the custom made saddle pillow intervention. NPRS: Numerical pain rating scale, PND: Postnatal day 
Table 2: Within control group (B) for comparing pain and sitting duration

\begin{tabular}{|c|c|c|c|c|c|}
\hline \multirow[t]{3}{*}{ Study groups } & \multicolumn{4}{|l|}{ Paired samples test } & \multirow[t]{3}{*}{ Significant (two-tailed) } \\
\hline & \multirow[t]{2}{*}{ Mean \pm standard deviation } & \multirow[t]{2}{*}{ Standard error mean } & \multicolumn{2}{|c|}{$\begin{array}{l}95 \% \text { confidence } \\
\text { interval of the } \\
\text { difference }\end{array}$} & \\
\hline & & & Lower & Upper & \\
\hline \multicolumn{6}{|l|}{ Pair 1} \\
\hline B pre NPRS - B post-NPRS 1 & $1.600 \pm 0.843$ & 0.267 & 0.997 & 2.203 & $0.001^{*}$ \\
\hline \multicolumn{6}{|l|}{ Pair 2} \\
\hline B post-NPRS 1 - B post-NPRS 2 & $2.700 \pm 0.949$ & 0.300 & 2.021 & 3.379 & $0.001^{*}$ \\
\hline \multicolumn{6}{|l|}{ Pair 3} \\
\hline B PND 0-1 hrs - B PND 1-2 hrs & $-1.1500 \pm 1.0288$ & 0.3253 & -1.8859 & -0.4141 & $0.006^{*}$ \\
\hline
\end{tabular}

*Significance at $95 \%$ confidence interval. Since the $\mathrm{p}$ value is less than 0.05 , there is a significant difference within the control group regarding the pain (using NPRS) and duration of sitting. NPRS: Numerical pain rating scale, PND: Postnatal day

Table 3: Independent comparison between Group A and Group B (for pain)

\begin{tabular}{|c|c|c|c|c|c|c|c|c|c|}
\hline \multicolumn{10}{|c|}{ Independent samples test } \\
\hline \multirow[t]{3}{*}{ Study groups } & \multicolumn{2}{|c|}{$\begin{array}{l}\text { Levene's test } \\
\text { for equality of } \\
\text { variances }\end{array}$} & \multicolumn{7}{|c|}{ t-test for equality of means } \\
\hline & \multirow[t]{2}{*}{$\mathbf{F}$} & \multirow[t]{2}{*}{ Significant } & \multirow[t]{2}{*}{$\mathbf{t}$} & \multirow[t]{2}{*}{ df } & \multirow[t]{2}{*}{ Significant (two-tailed) } & \multirow[t]{2}{*}{$\begin{array}{l}\text { Mean } \\
\text { difference }\end{array}$} & \multirow[t]{2}{*}{$\begin{array}{l}\text { Significant } \\
\text { error difference }\end{array}$} & \multicolumn{2}{|c|}{$\begin{array}{l}95 \% \\
\text { confidence } \\
\text { interval of the } \\
\text { difference }\end{array}$} \\
\hline & & & & & & & & Lower & Upper \\
\hline \multicolumn{10}{|l|}{ Post-NPRS 1} \\
\hline $\begin{array}{l}\text { Equal variances } \\
\text { assumed }\end{array}$ & 1.864 & 0.187 & -2.727 & 20 & $0.013^{*}$ & -0.750 & 0.275 & -1.324 & -0.176 \\
\hline $\begin{array}{l}\text { Equal variances not } \\
\text { assumed }\end{array}$ & & & -2.592 & 13.470 & $0.022^{*}$ & -0.750 & 0.289 & -1.373 & -0.127 \\
\hline \multicolumn{10}{|l|}{ Post-NPRS 2} \\
\hline $\begin{array}{l}\text { Equal variances } \\
\text { assumed }\end{array}$ & 1.052 & 0.317 & -5.199 & 20 & $0.000^{*}$ & -1.633 & 0.314 & -2.289 & -0.978 \\
\hline $\begin{array}{l}\text { Equal variances not } \\
\text { assumed }\end{array}$ & & & -5.086 & 17.044 & $0.000^{*}$ & -1.633 & 0.321 & -2.311 & -0.956 \\
\hline
\end{tabular}

Table 4: Independent comparison between Group A and Group B (for duration of sitting)

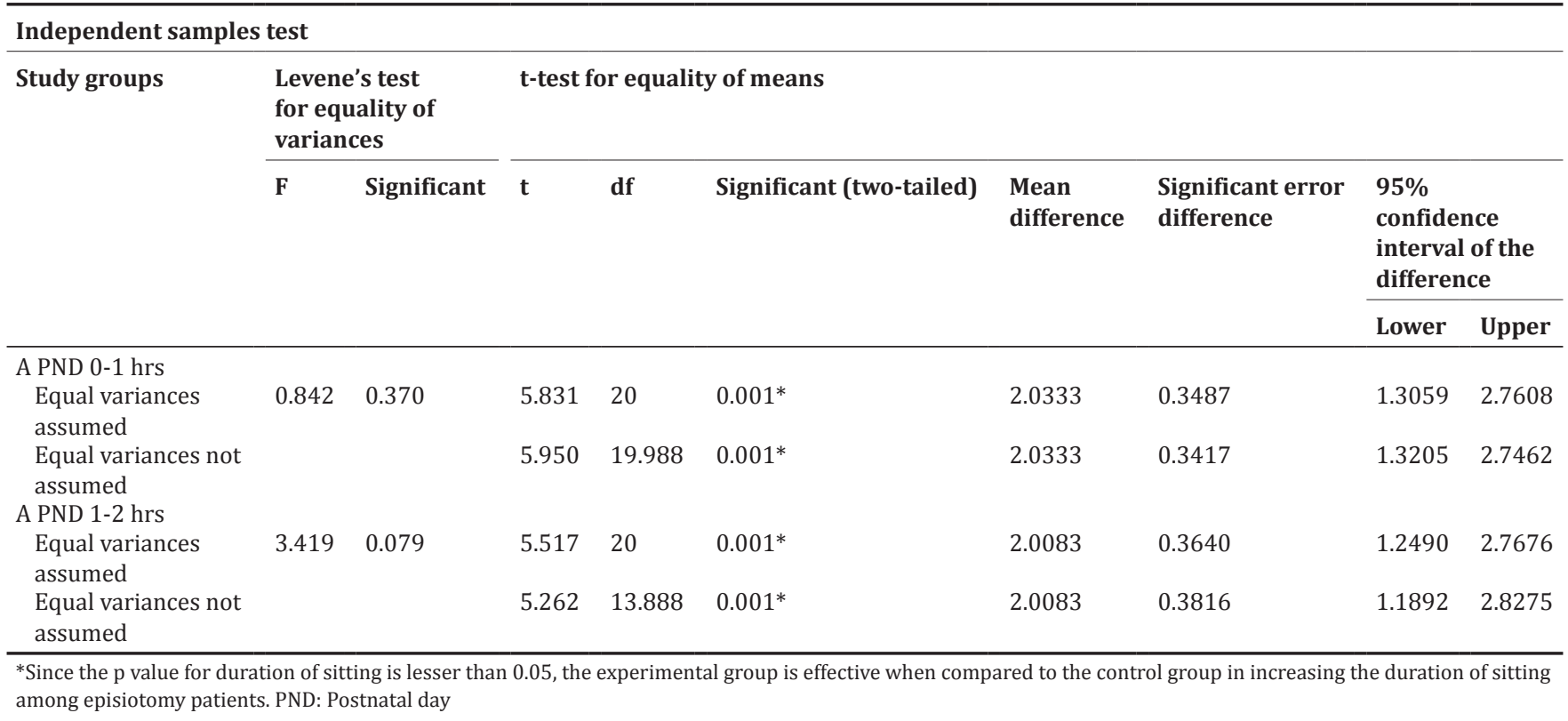

tolerance and enhances breastfeeding thus promoting health status, life satisfaction, and well-being.
One of the limitations of the study was that the single pillow size (regular) was used for all the patients uniformly, so in the future, 
size can be given more importance to increase the comfortableness of the pillow. Furthermore, ischium measurements can be taken into consideration for wider pelvis patients.

\section{CONCLUSION}

The current study emphasizes the usage of the customized saddle pillow for postnatal mothers, who have undergone episiotomy, by reducing perineal pain as well as enhancing breastfeeding.

\section{REFERENCES}

1. Kaviani M, Sepasi S, Azima S, Emamghoreishi M, Asadi N, Haghpanah S. The effects of olive leaf extract ointment on pain intensity and EARLY maternal complications in Primiparous women. Int J Pharm Pharm Sci 2017;9(7):31-4.

2. Singh S, Thakur T, Chandhiok N, Dhillon BS. Pattern of episiotomy use and its immediate complications among vaginal deliveries in 18 tertiary care hospitals in India. Indian J Med Res 2016;143(4):474-80.

3. Azhari S, Aradmehr M, Rakhshandeh H, Tara F, Shakeri MT. The effects of chamomile cream on wound healing of episiotomy in Primiparous women. Iran J Obest Gynecol Infertil 2014;93:16-26.
4. Golmakani N, Motlagh ER, Tara F, Asili J, Shakeri MT. The effects of turmeric (Curcuma longa L.) ointment on the healing of episiotomy site in Primiparous women. Iran J Obest Gynecol Infertility 2009;4:29-38

5. Khadivzadeh T, Molkizadeh M, Rakhshandeh H, Khajedaloui M. The impact of Lavender cream on episiotomy pain and wound healing in Primiparous women. J Mashhad Sch Nurs Midwifery 2009;1:19-24.

6. Belezaa AC, Ferreira CH, Driusso P, Santos CB. Effect of cry therapy on relief of perineal pain after vaginal childbirth with episiotomy: A randomized and controlled clinical trial. Physiotherapy. http://dx.doi. org/10.1016/j.physio.2016.03.0030031-9406/(2016.

7. Alvarenga MB, de Oliveira SM, Francisco AA, da Silva FM, Sousa M, Nobre MR. Effect of low-level laser therapy on pain and perineal healing after episiotomy: A triple-blind randomized controlled trial. Lasers Surg Med 2017;49(2):181-8.

8. Lirette LS, Chaiban G, Tolba R, Eissa H. Coccydynia: An overview of the anatomy, etiology, and treatment of coccyx pain, academic division of ochsner clinic foundation. Ochsner J 2014;14(1):84-7.

9. Reading AE, Sledmere CM, Cox DN, Campbell S. How women view post episiotomy pain. Br Med J (Clin Res Ed) 1982;284(6311):243-6.

10. Alomar MJ. Factors affecting postpartum depression among women of the UAE and Oman. Int J Pharm Pharm Sci 2015;7(7):231-3. 